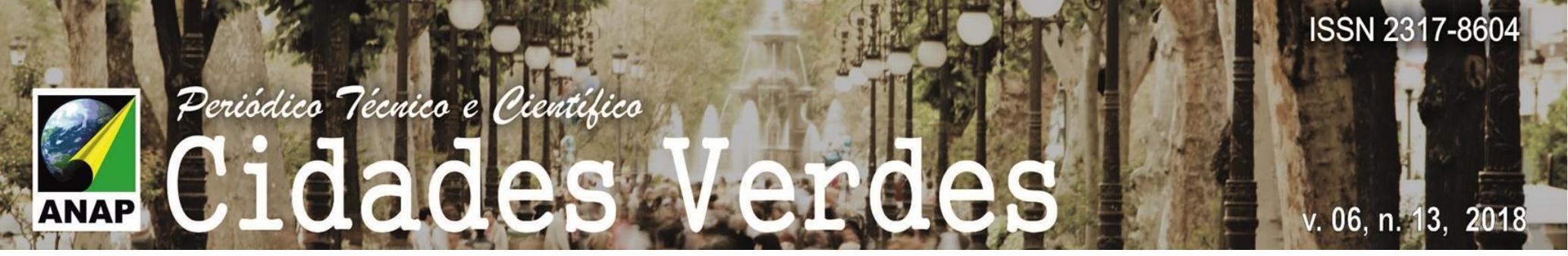

\title{
Gerenciamento de resíduos sólidos, efetivação da lei no 12.305/2010 no município de Pires do Rio - GO
}

Administration of solid residues, efetivação of the law no. 12.305/2010 in the municipality of Pires do Rio - GO

La administración de residuos sólidos, eficacia de la ley no 12.305 / 2010 en el municipal distrito de Pires del Rio - GO

Paulo Jean Pereira Alves

Mestrando em Geografia, UFG, Brasil. paulo.jean@ifgoiano.edu.br

Darliton Machado da Rocha Cursando Engenharia Agrícola no Instituto Federal Goiano- Campus Urutaí darlitonmchd@outlook.com

Anna Sarah Soares Alves Mestranda em Geografia, UFG, Brasil. annasarah03@hotmail.com

Odelfa Rosa Professora Doutora, UFG, Brasil. rosaodelfa@gmail.com 


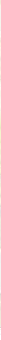

\section{RESUMO}

Este trabalho busca verificar a efetivação da Política Nacional de Resíduos Sólidos (Lei n.12.305/2010) no município de Pires do Rio - GO. O texto aborda todo processo de gestão de resíduos realizado pela Prefeitura Municipal, desde a coleta até a disposição final, verificando nesse percurso, a percepção da população, e a ação do poder público municipal. Através de questionários distribuídos para a população em diferentes bairros, sendo solicitado aos entrevistados seu preenchimento e posterior entrega, tendo em vista, a liberdade de resposta e a não identificação dos entrevistados. E pelo poder público com Leis fornecidas pela Secretaria de Meio Ambiente municipal. O trabalho tem como objetivo fornecer aos gestores informações para um melhor planejamento e gestão urbana dos resíduos sólidos, a fim de se adequar à Lei 12.305/2010, e com isso proporcionar uma melhor qualidade de vida a população.

Palavras-chaves: Resíduos sólidos urbanos. Lei 12.305/2010. Cidade.

\section{ABSTRACT}

This paper surchs to verify the effectiveness of the National Solid Waste Policy (Law n.12.305 / 2010) in the municipality of Pires do Rio - GO. The text includes all waste management processes carried out by the municipal government, from the collect to the final disposal verifying the way of perception of the population and the action of the municipal public power. Through questionnaires distributed to the population in different districts, being asked to the interviewee filling out the form and subsequent delivery, aiming for freedom of reply and identification of respondents. And by the public power with Laws provided by the Municipal Environment.The objective of this paper is to provide managers information to better planning and urban management of solid waste in order to comply with the Law 12,305 / 2010, and with it a better quality of life for the population.

Keywords: Solid urban waste. Law 12,305 / 2010. City.

Resumen

El presente estudio se deriva del trabajo que verifica el efetivação de la política nacional de residuos sólidos ( $\mathrm{n}$ ㅇ de ley.12.305 / 2010) en el municipal distrito de Pires do Rio - GO. El texto aborda todo proceso de gestión de residuos realizado por el Ayuntamiento Municipal, desde la recolección hasta la disposición final, verificando en ese recorrido la percepción de la población, y la acción del poder público municipal. A través de cuestionarios distribuidos para la población en vecindarios diferentes, serlo pide la terminación y la entrega siguiente a sus entrevistados sus, tend en la visualización, la libertad de respuesta y la non identificación de los entrevistados. Y por el poder público con Leyes proporcionadas por la Secretaría de Medio Ambiente municipal. El trabajo tiene como objetivo proporcionar a los gestores información para una mejor planificación y gestión urbana de los residuos sólidos a fin de adecuarse a la Ley 12.305 / 2010, y con ello proporcionar una mejor calidad de vida a la población.

Palabras clave: Residuos sólidos urbanos; Ley 12.305 / 2010; ciudad. 


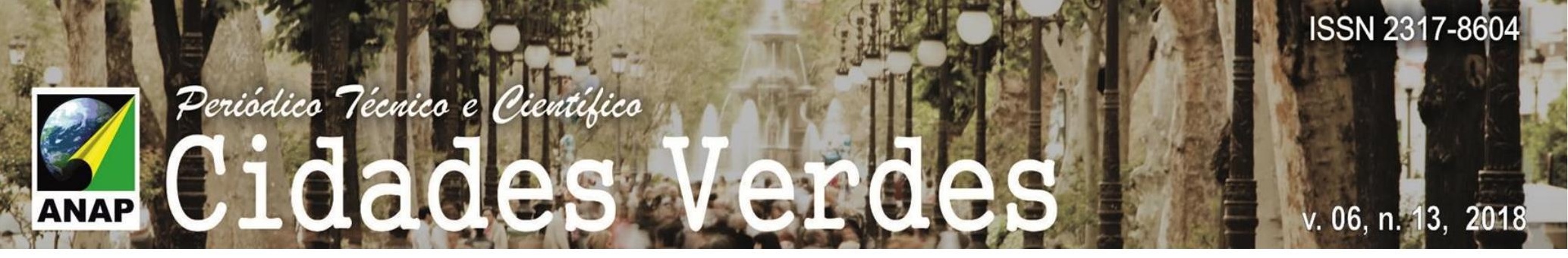

\section{INTRODUÇÃO}

O grande aumento na produção de resíduos e o desenvolvimento urbano acelerado, tem sido uma preocupação de ordem mundial, devido à dificuldade encontrada pelos governantes de manter uma economia sustentável que reduza as consequências socioambientais (MONTEIRO e ZVEIBIL, 2001; ABRAMOVAY et. al., 2013). Dentre essas consequências encontradas atualmente, está a dificuldade da gestão de resíduos, pois aproximadamente $90 \%$ da população mundial se alimenta basicamente de produtos industrializados é por tanto geram um elevado percentual de resíduos sólidos a serem geridos pelos órgãos públicos (IBAM, 2007; ANDREOLI et. al., 2014).

Resíduos Sólidos Urbanos (RSUs, de acordo com a norma NBR.10.004 da Associação Brasileira de Normas Técnicas - ABNT), vulgarmente denominados como lixo urbano, são resultantes da atividade doméstica e comercial dos centros urbanos. As composições dos resíduos sólidos urbanos são diversificadas, sendo definida de acordo com as características de cada município ou comunidade onde é produzido. A localização da cidade, suas atividades industriais, agrícolas e comerciais, além das condições socioeconômicas da população são alguns dos fatores que determinam as características dos resíduos sólidos urbanos de um município. Esses resíduos podem ser classificados das seguintes maneiras.

Resíduos Classe I - Perigosos - São aqueles que apresentam periculosidade e características como inflamabilidade, corrosividade, reatividade, toxicidade e patogenicidade. Consulte a NBR para maiores detalhes sobre cada característica enquadrada nessa classificação.

Resíduos Classe II - Não Perigosos - A) Resíduos Classe II A - Não Inertes: São aqueles que não se enquadram nas classificações de resíduos classe I - Perigosos ou de resíduos classe II B Inertes. Os resíduos classe II A - Não inertes podem ter propriedades, tais como: biodegradabilidade, combustibilidade ou solubilidade em água. B) Resíduos Classe II B Inertes: São quaisquer resíduos que, quando amostrados de uma forma representativa e submetidos a um contato dinâmico e estático com água destilada ou desionizada, à temperatura ambiente não tiverem nenhum de seus constituintes solubilizados a concentrações superiores aos padrões de potabilidade de água, excetuando-se aspecto, cor, turbidez, dureza e sabor, conforme anexo G da NBR 10004.

No Brasil a falta de execução de uma gestão de resíduos sólidos efetiva, tem sido a causa de grandes problemas ambientais, afetando diretamente o meio ambiente (SILVEIRA e GERMANO, 2011). Segundo Pires (2015), o equacionamento destes problemas no país é verificado desde sua produção, coleta e disposição final. Evidenciando a necessidade da adoção de medidas adequadas para o seu gerenciamento, tendo em vista a prevenção e a minimização de danos aos recursos naturais, conforme proposto pela Política Nacional de Resíduos Sólidos - PNRS, além da Política Nacional de Meio Ambiente (PINTO, 1999; SIQUEIRA e MORAES, 2009).

Benjamin (2008) e MMA (2012) destaca que a proteção do meio ambiente é não só dever dos governantes de um determinado país, mas também é tutelada a toda população. Essa responsabilidade civil compartilhada, conforme determinado pelo artigo 25 da Lei Federal no 12.305 de 12 de agosto de 2010, destaca que para haver uma conservação e preservação 


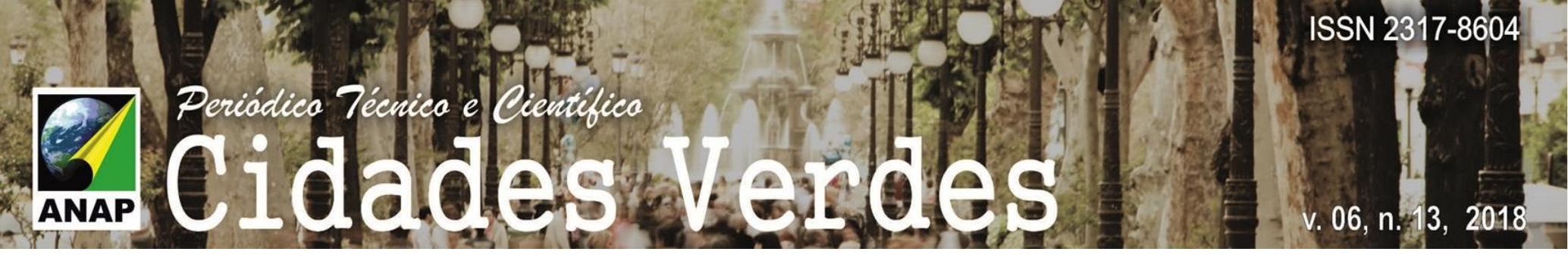

eficaz do ambiente, bem como da própria consolidação de normativas e medidas ambientais, a sociedade deve estar inserida em conjunto com seus representantes (CARDOSO, 2015; GOUVEIA, 2014). Por outro lado na prática conforme defendido, por Braga e Dias (2008), em muitos casos nem a sociedade e tão pouco as ações públicas brasileiras adotam e cumprem as leis ambientais promulgadas.

\section{OBJETIVO}

Verificar a efetivação da Lei 12.305/2010, no município de Pires do Rio - GO, bem como avaliar os pontos positivos e negativos da gestão de resíduos sólidos.

\section{METODOLOGIA}

A pesquisa é de cunho descritiva e exploratória, numa abordagem quantitativa e foi desenvolvida entre os meses de agosto e novembro 2017, na cidade de Pires do Rio - GO, com intuito de identificar a efetivação da Lei $12.305 / 10$ no município, bem como verificar o conhecimento popular da gestão ambiental de resíduos exercida pela política municipal. Assim, para a escolha das respostas foi utilizado um questionário contendo 10 perguntas objetivas, distribuídas em diferentes bairros da cidade. A cidade de Pires do Rio (GO), é composta por quarenta e nove (49) bairros, a maioria pavimentada, contando com serviço de saneamento básico e coleta de lixo. Após visitas pela cidade, quatro (4) bairros foram escolhidos. Para chegar a escolhas desses bairros foram realizadas visitas por quatro (4) semanas consecutivas, onde foi observado que os RSUs, pelos lotes baldios e calçadas, sempre presentes. Os bairros são Setor Central, que ainda tem vários lotes baldios, Setor dos Bancários, que é um setor nobre, com coleta diária, têm vários lotes baldios o que facilita a disposição irregular de RSUs, Bairro Dr. Nadin Saud bairro periférico, recentemente pavimentado, com várias áreas de disposição irregular de RSUs, e por final Vila Hene Saud, é um vila habitacional, como nos demais servida de serviço de limpeza público, o que não impede a ação irregular de disposição de RSUs em locais impróprios.

Os dados necessários para a caracterização dos RSUs na cidade, foram obtidos por meio de entrevistas com os moradores e visitas domiciliares. Os questionários buscaram reunir informações diversas acerca do sistema de coleta dos RSUs na cidade de Pires do Rio - GO, tais como: Existe serviço de coleta de resíduos sólidos no seu bairro? Qual é o tipo de veículo utilizado na coleta domiciliar direta de resíduos sólidos (caminhões, tratores...)? Como é feita a cobrança pelos serviços de coleta (direta e indireta) de resíduos sólidos? Qual é a destinação final do lixo coletado (aterro sanitário, lixão...)? A unidade de destinação final é licenciada? No município, existe algum programa de educação ambiental destinado à conscientização acerca do lixo? Podendo ser em parcerias com a Secretaria de Meio Ambiente e Educação. 0 município possui um sistema de informações ambientais, com dados sobre a gestão de resíduos sólidos, disponível? No município, existe PMGIRS - Plano municipal de Gestão Integrada de Resíduos Sólidos aprovado por meio de Lei Municipal? Na sua opinião, a política nacional de resíduos sólidos Lei n. 2. 305/2010 está sendo corretamente efetivada no 


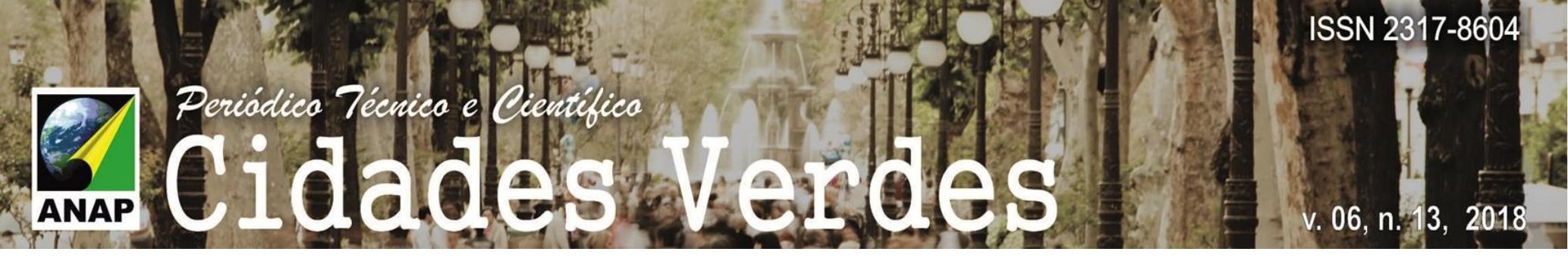

município? Na sua opinião, quais as principais deficiências e o que precisa melhorar na gestão de resíduos em seu município?

A pesquisa foi distribuída em diferentes setores, sendo solicitado aos entrevistados, o seu preenchimento e a sua posterior entrega, tendo em vista a liberdade de resposta. Foi assim amostrado um média de 150 indivíduos aleatoriamente de forma voluntária.

As respostas foram analisadas verificando simultaneamente as ideias chave nos discursos da população local, comparando significados numéricos e verbais. Deste modo a analise seguiu as seguintes etapas: Leitura exploratória (levantamento das palavras chaves) como fonte primária, será realizada uma pesquisa teórica acerca da temática abordada ainda será buscado autores que tecem estudos e discussões pertinentes ao tema proposto como: ABRAMOVAY (20130; ANDREOLI (2014); BRAGA e DIAS (2008); CARDODO (2015) GOUVEIA (2014), entre outros; Associação de qualidades com conceitos e apuramento dos significados numéricos das expressões indicadoras das características analisadas.

Os dados obtidos nos questionários foram tabulados com o uso do programa Microsoft Office Excel 2007. Após a tabulação das informações, os valores médios foram utilizados para obtenção das análises descritivas através de gráficos.

Já para a verificação concreta da existência da Política Nacional de Resíduos Sólidos (Lei n.12.305/2010) no município de Pires do Rio - GO, foi utilizando as leis ambientais fornecidas pela Secretária do Meio Ambiente da cidade analisada. Comparando-as com informações da Lei Federal vigente, presente em livros, cartilhas, manuais e artigos.

\section{RESULTADOS E DISCUSSÃO}

Nas últimas décadas, o redescobrimento dos resíduos sólidos como um problema eminentemente social incita novos questionamentos. Quanto a frequência da coleta domiciliar direta de resíduos sólidos de Pires do Rio - GO, averiguou-se que em $62 \%$ dos casos, a coleta é realizada 3 vezes por semana e diariamente, em 17\% dos casos. Em que, por conseguinte $38 \%$ da população entrevistada destaca que a Prefeitura adota o sistema de coleta direta em toda a cidade, tendo uma taxa semelhante de $33 \%$ que não sabem se a coleta ocorre em todo o município ou se atinge apenas partes chaves.

Entende-se assim pela legislação ambiental que a cidade de Pires do Rio - GO, cumpre com o seu papel quanto tratado do manuseio dos resíduos sólidos. Destacando que os órgãos municipais, desde que adotem a coleta direta de resíduos sólidos, tem a autonomia para gerir o período para a coleta, contudo por mais que o seu papel seja executado, a gestão pública, não representa em suas documentações fornecidas como mencionada pelo Secretaria Municipal de Meio Ambiente, aparato legal referente a coleta ou destinação final de resíduos.

Segundo a população o transporte dos resíduos sólidos é efetuado pelo órgão municipal encarregado da limpeza urbana. Notando-se que $81 \%$ dos indivíduos questionados, informaram que a Prefeitura utiliza caminhões prensa, seguido de $15 \%$ caminhões abertos e $4 \%$ não sabe como ocorre o recolhimento dos resíduos.

Para esses serviços, podem ser usados recursos próprios da prefeitura, de empresas sob contrato de terceirização ou sistemas mistos, como o aluguel de viaturas e a utilização de mão 


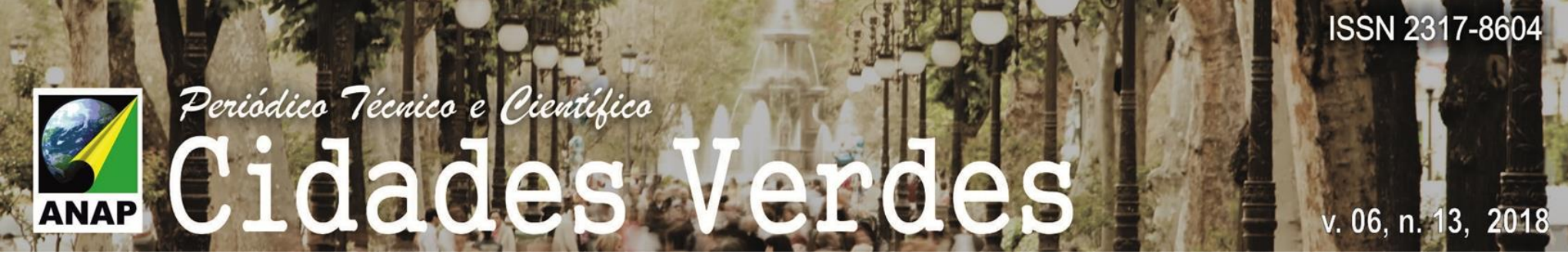

de obra da prefeitura (IBAM, 2016). O transporte dos resíduos do local de coleta para o destino final deve ser feito com equipamentos específicos, os quais atendam as especificações de cada tipo de resíduo (BRASIL, 2008). No caso de Pires do Rio - GO, toda a coleta de resíduos sólidos são feitas pela Prefeitura municipal, utilizando dois (2) caminhões compactadores, e u (1) caminhão aberto, com exceção dos resíduos da construção civil que é feito por uma empresa terceirizada.

No Brasil a escolha do veículo coletor é realizada pela natureza e qualidade do lixo, as condições de operação do equipamento, o preço de aquisição, facilidade em adquirir peças de reposição, pelos custos de operação, manutenção e pela condição de tráfego da cidade (MMA, 2016). Assim, os veículos indicados pelo MMA (Ministério do Meio Ambiente), para as atividades de coleta devem atender a estrutura física da cidade, atentando na diminuição da poluição atmosférica e visual, bem como o risco de acidentes (MANSUR e MONTEIRO, 2016). Segundo o mesmo autor em cidades pequenas, como Pires do Rio - GO, onde a população não é aglomerada, os equipamentos mais indicados devem ser sem compactação, pois possibilita a sua utilização em outros serviços do Município.

Foi verificado pela análise do questionário aplicado na Cidade de Pires do Rio - GO, que 100\% da população afirma a existência do serviço de coleta de resíduos sólidos no município. De acordo com a figura 01 apenas $56 \%$ acredita que o serviço prestado pela gestão pública é sem cobrança. Deste modo 3\% dos entrevistados não sabem ou não tem informação se a prefeitura local realiza algum tipo de cobrança, seguido por $41 \%$ da população que acredita que a cobrança ocorre de alguma forma anualmente ou mensalmente. 


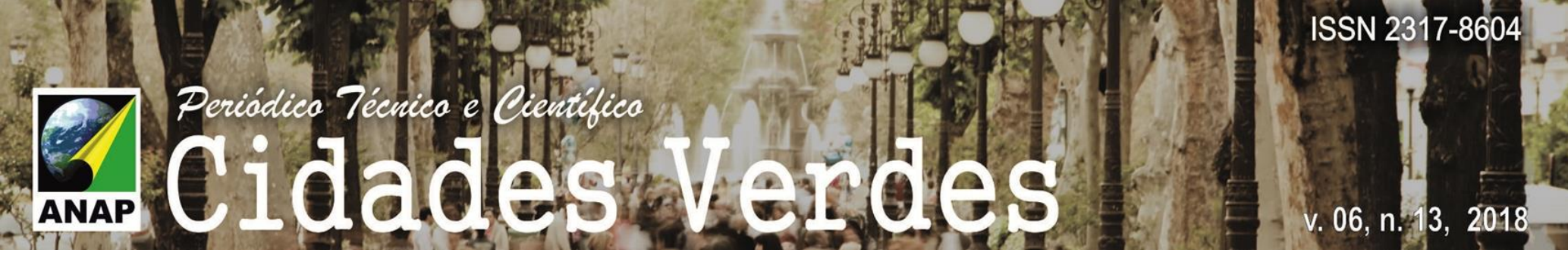

Figura 1. Existência de cobrança pela coleta

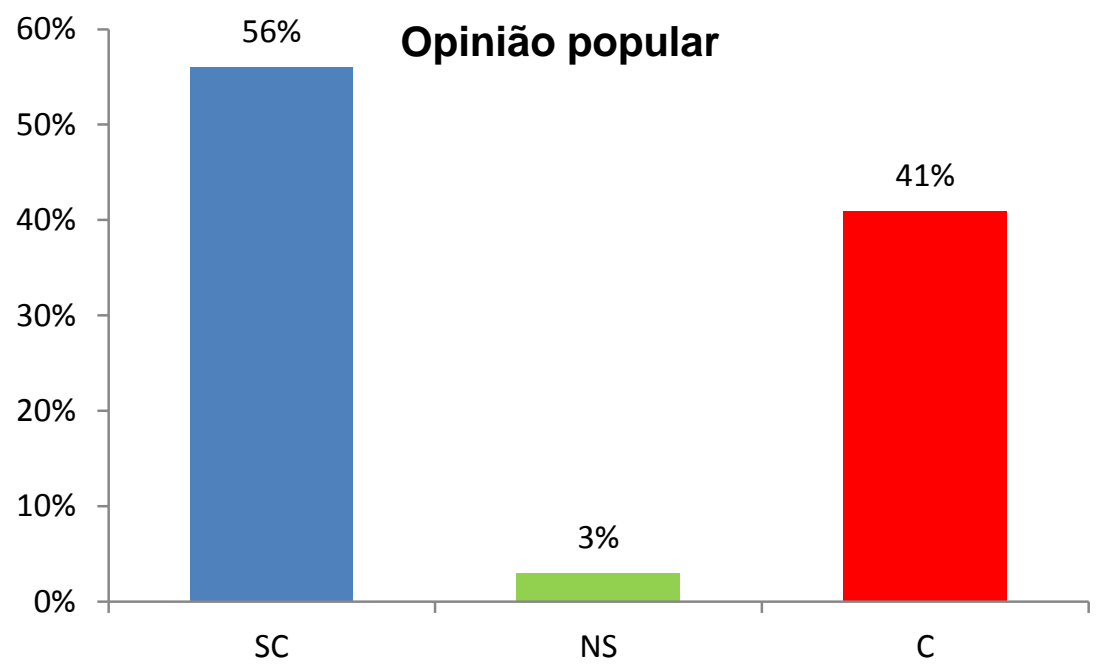

(NS) Não sabe da existência de nenhum cobrança;

(C) Sim, acreditam que há cobrança de alguma forma;

(SC) Acreditam que não há cobrança.

Para o IBGE (2008), no Brasil cerca de 3.285 municípios já fazem a cobrança pelos serviços de coleta e destinação final dos resíduos sólidos urbanos, em conjunto com o Imposto Predial e Territorial Urbano - IPTU. Pois segundo o Plano Nacional de Resíduos Sólidos - PNRS e o Plano Estadual de Resíduos Sólidos De Goiás -PERS/GO, conforme previsto na Política Nacional de Resíduos Sólidos (Lei n.12.305/2010), determinam que os Planos Municipais de Gestão Integrada de Resíduos Sólidos - PMGIRS devem obrigatoriamente ter um sistema de cobrança, previsto para o custo da prestação de serviços públicos, seja ele para a limpeza das vias urbanas ou para o manejo e destinação dos resíduos sólidos da cidade (PNRS, 2011.; PERS/GO, 2016.; BRASIL, 2010).

Porém ao se verificar as Leis ambientais fornecidas pela Secretária do Meio Ambiente da cidade de Pires do Rio - GO, foi observado a inexistência de qualquer documento legislativo que evidencie a prática de cobrança no município. Também, não foram encontrados em qualquer outro mecanismo como o site da prefeitura, informações sobre a existência ou não destas taxas não foi possível determinar se o município realiza algum tipo de cobrança, mesmo junto com o IPTU como determinado pela Lei Federal e Estadual.

Em relação à destinação final dos resíduos sólidos, o Instituto Brasileiro de Geografia e Estatística (IBGE), afirma que na maioria das cidades brasileiras os resíduos sólidos urbanos são coletados pelo serviço de limpeza urbana municipal e descartado em lixões sem qualquer cuidado e tratamento adequado, pelo fato do custo ser baixo para as prefeituras (IBGE, 2012). Todavia de acordo com a lei 12.305/10 até o ano de 2014, deveria ser erradicado os lixões no Brasil, estando associados à inclusão social, preservação ambiental e à emancipação econômica de coletores de materiais reutilizáveis e recicláveis (BRASIL, 2010). 


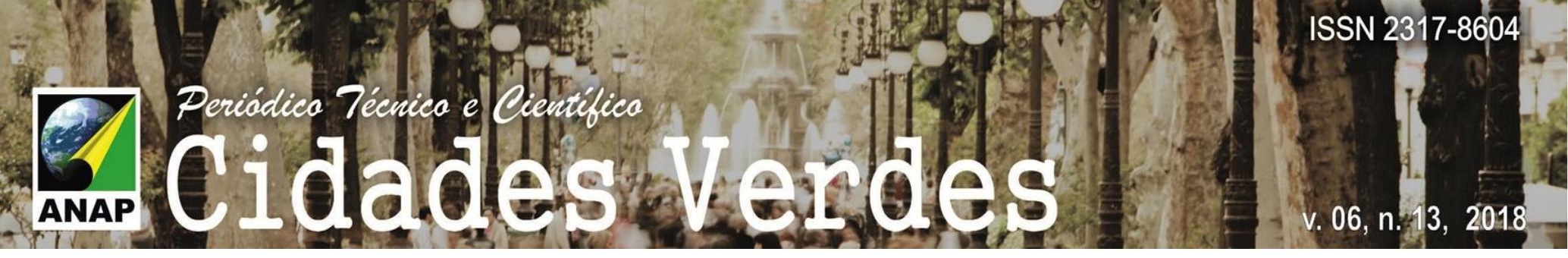

Importa salientar que ao se questionar a população acerca deste panorama, $87 \%$ dos entrevistados acreditam que o destino final dos resíduos é o lixão e $13 \%$ para o aterro sanitário. Em Goiás dos 246 municípios goianos, apenas 11 conseguiram construir seus aterros sanitários, mas destes 6 possuem licenciamento para funcionar, o IBGE (2008) e (2015), destaca ainda, que no Brasil a metade dos seus municípios 5.564 ainda depositam seus resíduos em lixões, sendo o percentual de cidades que dispõem em aterros controlados legalizados, permaneceu estagnado nos 8 anos, 22,3\% em 2000 e 22,5\% em 2008.

Conforme o secretário de Meio Ambiente, o município, dispõe de aterro sanitário controlado. Apesar disto como descrito pela própria gestão pública, o aterro municipal não conseguiu cumprir com a meta proposta pela Política Nacional de Resíduos Sólidos, em que devido à falta de recursos a presente área não se encontra dentro do que manda a legislação Federal, o que faz com área destinada ao aterro sanitário controlado, seja apenas um lixão a céu aberto.

Outro ponto pertinente, é o desconhecimento dos entrevistados quanto ao licenciamento da unidade de destinação final, onde $64 \%$ não sabem se é licenciada e $34 \%$ afirmaram que sim, possui licenciamento. Deste modo, quanto ao licenciamento da unidade de destinação final é importante ressaltar a ausência de qualquer tipo de documentação municipal comprobatória da licença ambiental vigente, pois como mencionado pelo Governo de Pires do Rio - GO, o município, ainda não conseguiu se adequar as normativas federais e, portanto, não possui ainda sua licença, como explicitado anteriormente.

Quanto à existência de um programa de educação ambiental destinado a conscientização acerca dos resíduos sólidos, foram observados que uma taxa de $40 \%$ dos indivíduos que não conhecem nenhuma atividade exercida pela gestão pública acerca do tema abordado. Porém, um percentual de $39 \%$ conhece pelo menos uma ação. Com base nisto para verificar se a cidade possui algum projeto visando a conscientização, foi analisado as Leis municipais existes. De acordo com o Código de Posturas e Sanitário do Município (LEI COMPLEMENTAR № 044, DE 28 DE DEZEMBRO DE 2001), o governo municipal deve apresentar em sua legislação a pretensão da realização de campanhas educativas e de conscientização da população acerca dos resíduos sólidos gerados na zona urbana.

Com isso, acredita-se que o poder público exerce de alguma forma sua atividade, contudo, ainda, não atente todos os setores da cidade. Para SISNEA (2016), a educação ambiental deve ser empregada em todos os níveis e modalidades do processo educativo continuo da educação brasileira, sendo, portanto, não só o dever da gestão pública no geral, mas de todas as esferas educativas. Cabendo assim ao poder público, como instituído na Lei $\mathrm{N}^{\circ} 9.795$, de 27 de abril de 1999, em termos dos artigos 205 e 225 da constituição federal a definição de políticas públicas que englobem a espera ambiental, visando conservação, recuperação e melhoria do meio ambiente (PLANALTO, 1999).

Outro aspecto preocupante faz menção ao sistema de informações ambientais da cidade (figura 2), onde $48 \%$ não sabem ou não tem acesso aos dados sobre gestão de resíduos sólidos, $2 \%$ responderam que tem acesso a algum tipo de informação, $10 \%$ responderam que não tem nenhum acesso aos sistemas de informação, $40 \%$ responderam que existe, no entanto, este acesso é de uso interno da gestão. 


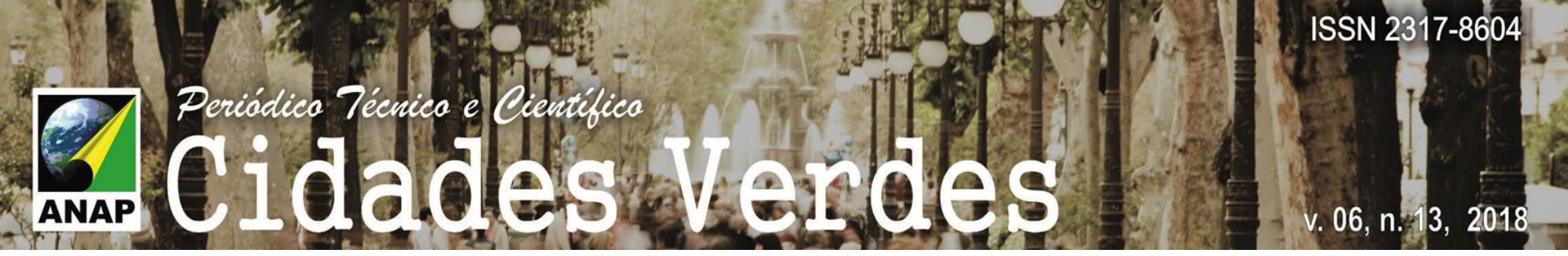

Figura 2. Existência de sistema de informações ambientais, sobre a gestão de resíduos sólidos.

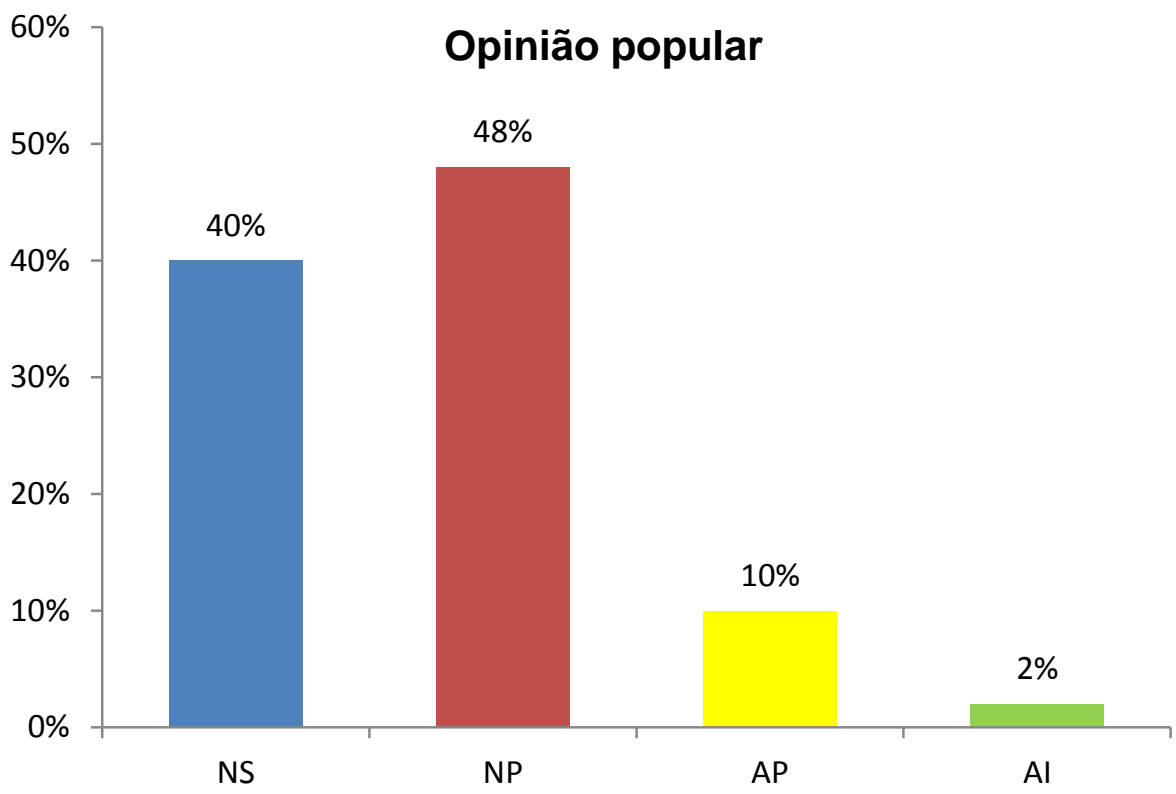

(NS) Não sabe da existência de nenhum banco de informações;

(NP) Não possui nenhum sistema de informação;

(AP) existe, sendo de acesso público;

(Al) Existe, mas de acesso interno dos órgãos ambientais e públicos.

É evidente que a maioria da população não tem acesso as informações disponíveis, no poder público do município. Por tanto sugere-se a gestão pública de Pires do Rio - GO, a criação de uma página informativa, na qual possa ser informado a população o resultado do trabalho exercido, bem como de toda as normativas ambientais. Levando em consideração conforme determinado pela lei de acesso a informação pública, n. 12.527, de 18 de novembro de 2011, art. $3^{\circ}$, é assegurado a população o direito ao acesso a informação, que devem ser fornecidas em conformidades com os presentes nas administrações públicas (BRASIL, 2009; PLANALTO, 2011). Assim as gestões municipais devem mostrar de fácil acesso o trabalho quanto a proteção do meio ambiente.

Embasado na Lei no 12.305/10, foi questionado aos entrevistados sobre a existência no município do plano de gestão integrada de resíduos sólidos (PMGIRS), aprovado por meio de Lei municipal, $75 \%$ deles não sabem sobre sua existência e apenas $21 \%$ possuem conhecimento do plano de gestão de Pires do Rio - GO. Entretanto quando questionados sobre a sua efetivação no município apenas um percentual de $2 \%$ afirmam que a legislação vigente, está de acordo com as normativas ambientais Federais e Estaduais. Sendo assim uma média de $72 \%$ da população entrevistada não conhece a Lei, $21 \%$ acredita que as normas estão sendo parcialmente cumprida e $5 \%$ opina por não está sendo efetivada.

Porém, não foi encontrado ou repassado pela Secretaria do Meio Ambiente, o Plano de Gestão Integrada de Resíduos Sólidos do Município, sendo, portanto, impossível e incoerente determinar sua existência. Mas, até então pode constatar por meio do presente estudo, que a 


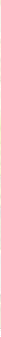

gestão municipal tem em sua legislação séries de déficits a serem superados. Já que pela Lei 12.305/2010 e de saneamento básico o PGIRS é um dos mais importantes instrumentos da política de resíduos sólidos de cada cidade brasileira, pois define os objetivos e metas especificas a serem cumpridas e executadas pela gestão e população (PNRS, 2011). O plano de gestão Integrada de resíduos sólidos também visa a geração de lucro econômico e social de forma sustentável, bem como o equilíbrio ambiental (BRASIL, 2009)

Assim considerando todos as informações anteriores coletadas pela entrevista, foi solicitado aos entrevistados a avaliação final acerca da política de gestão de resíduos existente no município, por meio de pontuação variando de 1 a 5 . Sendo 1 correspondente a péssimo, 2 a regular, 3 a bom, 4 a muito bom e 5 para uma avaliação ótima. Com base a estes parâmetros avaliativos $30 \%$ da população considera a gestão pública boa, 30\% péssima, 17\% regular, $16 \%$ muito bom e $7 \%$ ótima. Como podemos analisar na figura 3.

Figura 03. Avaliação da política de gestão de resíduos sólidos

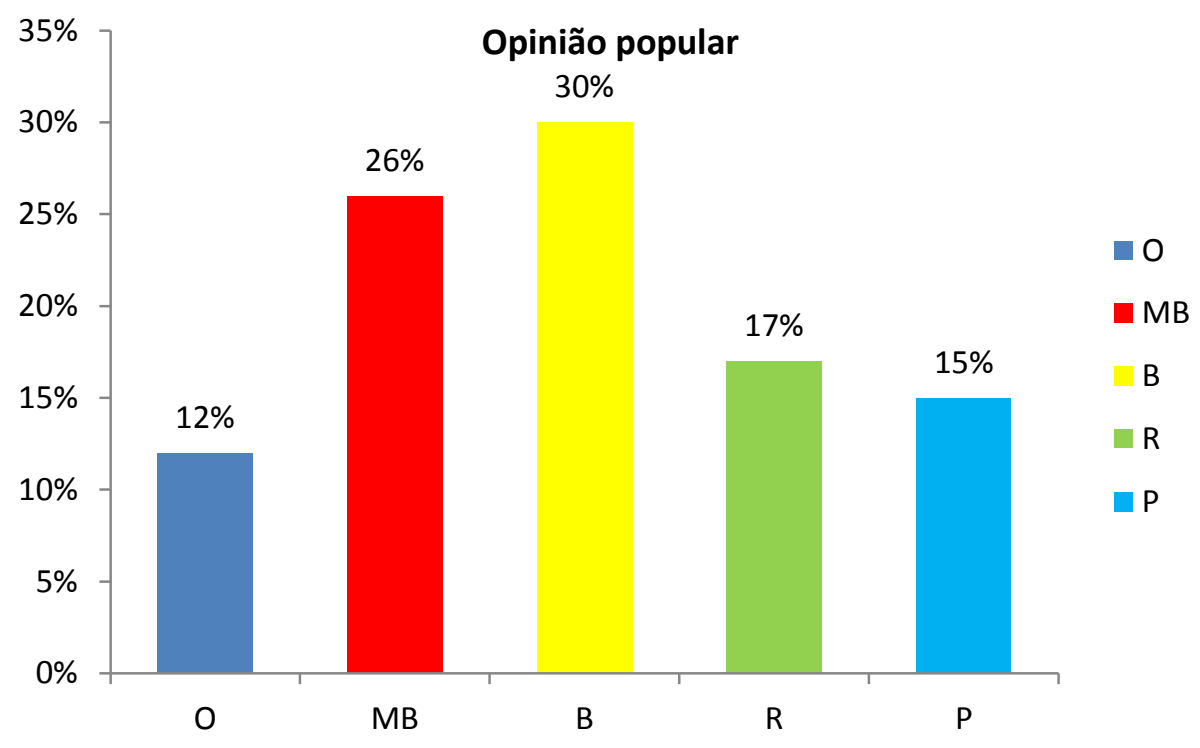

(B) Boa; (P) Péssima; (R) Regular; (MB) Muito Bom; (O) Ótima

Dessa forma, após análise observamos que o presente governo municipal deve melhorar quanto a coleta, abrangendo uma maior quantidade de bairros, bem como realizar programas de conscientização ambiental para toda a população. Além de realizar e cumprir com maior precisão a Lei de saneamento básico e de gerenciamento de resíduos sólidos no município. Convém salientar assim que este estudo é apenas preliminar, sendo por tanto necessário à sua continuação, para melhor compreensão da efetivação da política nacional de gerenciamento de resíduos sólidos (lei n. 12.305/2010) no município de Pires do Rio - GO. 


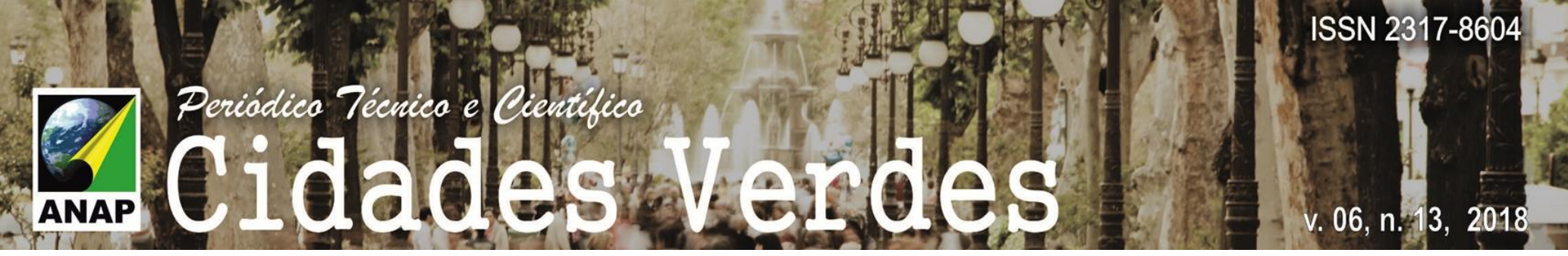

\section{CONCLUSÃO}

Diante do crescimento do município, se torna urgente, que esse assunto seja tratado de forma adequada, com gestão compartilhada, tecnologias adequadas, e principalmente, muita educação e comunicação ambiental. Não se trata apenas da deficiência do poder público municipal na efetiva realização da coleta e limpeza e destino final dos resíduos sólido do município, mas também na educação da população, pois em muitos bairros, a limpeza já foi realizada e, no entanto, moradores, depositam seus resíduos, tanto nas ruas como em terrenos baldios.

Para atingir uma maior efetivação da Lei no 12.305/10, a prefeitura poderia investir em projetos e campanhas, criando mecanismos de incentivo à coleta seletiva, claro que com essas medidas seria necessário a implantação de programa de comunicação e educação ambiental, que com certeza faria uma grande diferença na sociedade.

Como é destacado na Política Nacional de Resíduos Sólidos - PNRS, no art. 3으, inciso VII, o destino final ambientalmente adequado, a reutilização, reciclagem, compostagem, recuperação ou aproveitamento energético ou quaisquer outras destinações devem ser geridas e admitidas pelos órgãos competentes de cada município, sendo também legalizada em seu plano municipal de gestão integrada de resíduos sólidos (MPPR e SEMA-PR, 2013; BRASIL, 2012).

Por fim, sugere-se a gestão pública de Pires do Rio - GO, a criação de uma página informativa, na qual a população terá acesso a resultados do trabalho exercido, bem como de todas as normativas ambientais.

\section{REFERÊNCIAS BIBLIOGRÁFICAS}

ABRAMOVAY, Ricardo; SPERANZA, Juliana Simões; PETITGAND, Cécile. Lixo zero: Gestão de resíduos para uma sociedade mais próspera. São Paulo: Planeta sustentável: Instituto Ethos, 2013. 77P.

ANDREOLI, Cleverson Vitório; ANDREOLI, Fabiana de Nada; TRINDADE, Tamara Vigolo; HOPPEN, Cinthya. Resíduos sólidos: Origem, classificação e soluções para destinação final adequada. Coleção Agrinho, n.532, 2014. 22p.

BENJAMIN, Antônio Herman De Vasconcellos e. O meio ambiente na constituição federal de 1988. Informativo Jurídico da Biblioteca Ministro Oscar Saraiva, v.19, n.1, 2008.

BRAGA, Maria Cristina Borba; DIAS, Natália Costa. Gestão de resíduos sólidos urbanos. Curitiba, v.1, 2008.40p.

BRASIL. Lei no 12.305, de 2 de agosto de 2010. Institui a Política Nacional de Resíduos Sólidos; altera a Lei 9605 , de 12 de fevereiro de 1998; e dá outras providências.

CALDERONI, Sabetai. Os bilhões perdidos no lixo. São Paulo: Humanistas, 2 ed. 1998. 


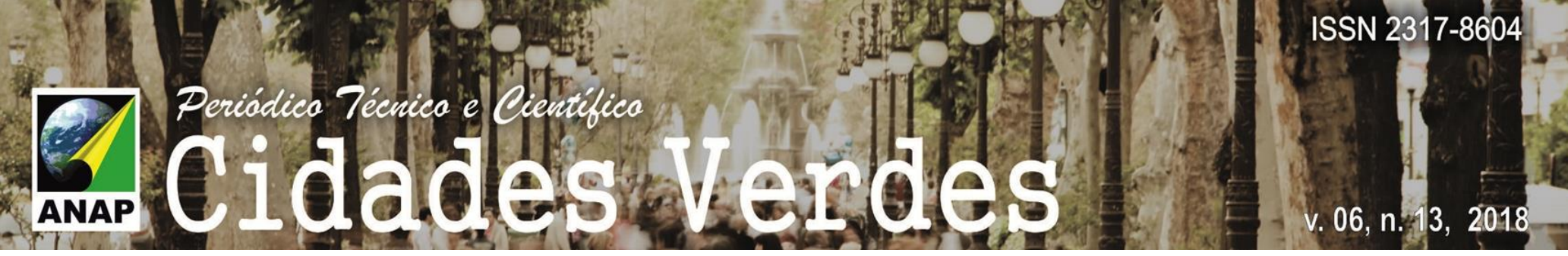

CARDOSO, Walace Hoffmann. A efetivação da política nacional de resíduos sólidos (Lei n.12.305/2010) no estado de Rondônia. Cacoal/RO: UNIR, (Dissertação de graduação), 2015. $59 f$.

CARDOZO, Mariana Caseño; LIEBER, Renato Rocha; DUTRA, Conceição Aparecida Matsumoto; BALESTIERI, José Antônio Perrella. Medidas de segurança em veículos para coleta de lixo urbano: Condições para manobra em ré. IN: XXV Encontro Nac. de Eng. de Produção: Porto Alegre, RS, Brasil, 2005. 8p.

Cartilha do Sistema Nacional de Educação Ambiental SISNEA, Ministério do Meio Ambiente, disponível no site: www.mma.gov.br, acesso em 17 de agosto de 2017.

GOUVEIA, Nelson. Resíduos sólidos urbanos: impactos socioambientais e perspectiva de manejo sustentável com inclusão social. Scielo, v.17, n.6, 2014.8p.

IBAM. Mecanismo de desenvolvimento limpo aplicado a resíduos sólidos: Gestão integrada de resíduos sólidos. IBAM: Ministério do Meio Ambiente, 2007.44p.

IBGE. Pesquisa nacional de saneamento básico. IBGE: Instituto Brasileiro de Geografia e Estatística, 2008. Disponível em: http://biblioteca.ibge.gov.br/visualizacao/livros/liv45351.pdf. Acesso em: 07 de outubro de 2017.

IBGE. Cidades. Instituto Brasileiro de Geografia e Estatística - IBGE. 2015. Disponível em: www.cidades.ibge.gov.br/xtras/home.php. Acesso em: 09 de outubro de 2017.

LEI ORGÂNICA DO MUNICÍPIO DE PIRES DO RIO, LEGISLATURA 2009/2012.

LEI COMPLEMENTAR № 120/14, DE 05 DE MARÇO DE 2014. Política Municipal do Meio Ambiente, seus fins e mecanismos de formulação e aplicação e constitui o Sistema e o Código Municipal do Meio Ambiente.

MANSUR, Gilson Leite; MONTEIRO, José Henrique R. Penido. Cartilha de limpeza urbana. CPU: Centro de Estudos e Pesquisas Urbanas do IBAM, convênio com a Secretaria Nacional de Saneamento - SNS - do Ministério da Ação Social - MAS, 2016.81p.

MMA. Lixo: Um grave problema no mundo moderno. MMA: Ministério do Meio Ambiente, 2016. 22p.

MONTEIRO, José Henrique Penido; ZVEIBIL, Victor Zular. Manual de Gerenciamento Integrado de resíduos sólidos. Rio de Janeiro: IBAM, 2011.200p. Disponível em: http://www.resol.com.br/cartilha4/manual.pdf. Acesso em: 07 de agosto de 2017.

MPPR e SEMA-PR. Centro de Triagem e Compostagem de Resíduos Sólidos Urbanos. Curitiba: Ministério Público Do Estado Do Paraná e Secretário Estadual do Meio Ambiente e Recursos Hídricos, Caderno de Especificações Técnicas e Desenho Técnico, 2ạ Ed., 2013. 58p.

NBR-10.004 DA Associação Brasileira de Normas Técnicas - ABNT - Resíduos Sólidos classificação. Válida a partir de 30/11/2004. 


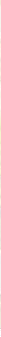

PERS/GO. Plano Estadual de Resíduos Sólidos: Projeto de destinação final de resíduos sólidos para a região Metropolitana e Municipal adjacentes Fase II. : Goiânia: Estado de Goiás, 2016. 52p. Disponível em: http://www.secima.go.gov.br/post/ver/200725/plano-estadual-deresiduos-solidos. Acesso em: 20 de setembro de 2017.

PINTO, Tarcísio de Paula. Metodologia para a gestão diferenciada de resíduos sólidos da construção urbana. São Paulo: USP (Tese de doutorado) 1999.189p.

PIRES, Silvia Helena M. Manual de Gestão de Resíduos Sólidos. Eletrobrás: Produto 8 - Versão Final, Brasília, 2015. 78p.

PLANALTO. Lei № 12.527, de 18 de novembro de 2011. Brasília: Previdência da república, 2011. Disponível em: http://www.planalto.gov.br/ccivil_03/_ato20112014/2011/lei/l12527.htm. Acesso em: 20 de setembro de 2017.

PLANALTO. Lei № 9.795, de 27 de abril de 1999. Brasília: Previdência da república, 2009. Disponível em: http://www.planalto.gov.br/ccivil_03/_ato2011-2014/2011/lei/l9795.htm. Acesso em: 20 de setembro de 2017.

PNRS. Plano Nacional de Resíduos Sólidos. PNRS: Governo Federal, Ministério Do Meio Ambiente, 2011. 109p.

SILVEIRA, Raquel Maria da Costa; GERMANO, Rachel Medeiros. As inovações da política nacional de resíduos sólidos e a responsabilidade civil pós-consumo. Revista Eletrônica: Natal, v.1, n.04, 2011.9p.

SIQUEIRA, Mônica Maria; MORAES, Maria Silvia de. Saúde coletiva, resíduos sólidos urbanos e os catadores de lixo. Ciênc. Saúde coletiva: Rio de Janeiro, v.14, n.6, 2009.9p. 